\title{
LA COMUNICACIÓN LINGÜÍSTICO-TEXTUAL Y EL PROBLEMA DE LA REFERENCIA
}

\author{
Manuel Maldonado Alemán
}

Generalmente, por referencia se entiende la relación que establecen los usuarios de las expresiones lingüísticas con un referente. La determinación de la condición de ese referente ha suscitado una interesante controversia en la que participan disciplinas como la lingüística, la psicología cognitiva, la sociología, la lógica e incluso la cibernética. Ello muestra que la referencia es un fenómeno complejo en el que intervienen aspectos semánticos, sintácticos, pragmáticos, lógicos y cognitivos. Es objetivo de este trabajo ofrecer, desde una perspectiva cognitiva, una reflexión sobre el fenómeno de la referencia a partir de una crítica al modelo sustancialista de la comunicación lingüístico-textual.

Si bien en 1933 el psicolingüista K. Bühler subraya en el llamado Organon-Modell, entre otras, la función representativa o referencial del lenguaje ${ }^{1}$, fueron C. K. Odgen y I. A. Richards quienes por primera vez utilizaron los términos de 'referencia' y 'referente', concretamente al configurar en la obra The Meaning of Meaning, aparecida en 1923, su famoso 'triángulo semiótico'. Su visión triangular del signo muestra una relación de significación compuesta por el símbolo ('symbol'), el pensamiento o referencia ('thought or reference') y el referente ('referent') ${ }^{2}$, por lo que todo signo lingüístico estaría constituido por un significante (la señal material que puede ser acústica o gráfica) y un significado (el sentido vinculado al significante), y poseerá además un referente (la realidad a la que apunta el signo, que puede estar compuesta por seres, estados, sucesos, acciones, situaciones o ideas). El pensamiento, concepto o significado enlaza el significante con el referente, de modo que un símbolo representa o está en lugar de un referente por medio de un pensamiento o concepto: aliquid stat pro aliqua re, según la definición escolástica que caracteriza esta visión del signo.

Partiendo del modelo de Odgen y Richards y usando la terminología de M. Black ${ }^{3}$, J. Lyons establece una distinción fundamental entre referencia ('reference') y sentido ('sense'), las dos manifestaciones principales del significado ${ }^{4}$. La referencia sería una relación

\footnotetext{
${ }^{1}$ Vid. K. Bühler, Sprachtheorie. Die Darstellungsfunktion der Sprache (Stuttgart: Fischer, 2a ed., 1965), p. 28.

2 Vid. C. K. Ogden/ I. A. Richards, The Meaning of Meaning (London: Routledge and Kegan Paul, 10 ed., 1966), p. 11.

3 Vid. M. Black, Language and Philosophy (New York: Cornell University Press, 1949).

${ }^{4}$ Vid. J. Lyons, Introduction to Theoretical Linguistics (Cambridge: University Press, 1968) pp. 404, 424 y 427. Vid. también J. Lyons, Semantics, (Cambridge: Cambridge University Press, 1977), vol. 1, pp. 174-177 y 206 y s.
} 
extralingüística concreta entre la expresión y el objeto (su referente). El sentido, en cambio, atañe a las relaciones intralingüísticas entre los lexemas de un mismo sistema lingüístico, o sea, a su diferenciación u oposición semántica con independencia de la relación con su referente. Relaciones semánticas como la sinonimia, homonimia, polisemia, hiponimia o antonimia, o bien, la atribución de rasgos sémicos como [ \pm nombre genérico], [ \pm contable], [ \pm animado], etc. corresponden, así, al ámbito del sentido de la expresión lingüística. La denotación, por el contrario, la tercera distinción que introduce Lyons, concierne al potencial referencial de un lexema, esto es, a la relación posible entre el lexema y su 'denotatum' o clase compuesta por personas, objetos, propiedades, etc., con los que aquél puede ser vinculado según las convenciones de una lengua natural:

By the denotation of a lexeme (and in the first instance we will discuss the notion of denotation in relation to lexemes) will be meant the relationship that holds between that lexeme and persons, things, places, properties, processes and activities external to the language-systems ${ }^{5}$.

Teniendo en cuenta que el término 'expresión lingüística' puede aludir a unidades lingüísticas de diferente complejidad -un lexema, una frase o un enunciado- ${ }^{6}$, H. Vater precisa, a partir de la diferenciación establecida por Lyons, que sólo la frase, sea ésta nominal, verbal o preposicional, y también el enunciado, pero no la palabra por sí misma en cuanto unidad léxica abstracta sin vinculación a un contexto lingüístico y situativo concreto, pueden emplearse para establecer relaciones de referencia. Esto es, "Wörter als abstrakte Lexikoneinheiten (Lexeme) referieren nicht; sie haben jedoch 'Denotation' <...>, d. h. ein Referenzpotential"7. Consiguientemente,

während Denotation an das einzelne Wort - und zwar als abstrakte Lexikoneinheit gebunden ist, kommt Referenz einer Phrase oder einen Satz zu, d. h. einem Ausdruck, der in einem konkreten Äußerungskontext verwendet wird; 'Sinn' ist in beiden Hinsichten neutral, d. h. sowohl mit einzelnen Wörtern (abstrakt oder im konkreten Äußerungskontext) als auch mit komplexen Ausdrücken verbunden ${ }^{8}$.

De este modo, por poner un ejemplo, a la unidad lexemática "rosa" le corresponde un denotatum o clase de referentes posibles (el conjunto de rosas existentes o imaginables) y un sentido (su peculiar valor sémico o conjunto de rasgos significativos que la distinguen de otros lexemas), pero no tiene referente concreto. Éste lo recibe únicamente en el uso discursivo al formar parte de un enunciado como "Juan regala a Carmen una rosa" en un

\footnotetext{
5 J. Lyons, Semantics, op. cit., p. 207.

${ }^{6}$ H. Vater define el término expresión lingüística como "eine zusammenfassende Bezeichnung für eine sprachliche Sequenz, die im Minimalfall aus einem einzigen Wort besteht, im Maximalfall aus einer Phrase oder einem Satz" [H. Vater, Einführung in die Zeit-Linguistik (Hürth/Efferen: Gabel, $3^{\text {a }}$ ed., 1994), p. 11].

7 H. Vater, «Referenzrelationen in Texten», en K. Brinker (ed.), Aspekte der Textlinguistik (HildesheimZürich-New York: Olms, 1991), pp. 19-53, aquí p. 25.

${ }^{8}$ H. Vater, Einführung in die Textlinguistik. Struktur, Thema und Referenz in Texten (München: Fink, 1992), p. 114.
} 
contexto lingüístico-situativo determinado, en el que también posee el sentido referido a su significado literal.

Por otro lado, J. S. Petöfi, tomando los términos 'Sinn' y 'Bedeutung' de G. Frege e introduciendo los conceptos 'Intension' y 'Extension' de R. Carnap9 ${ }^{9}$, adapta de la siguiente manera el triángulo semiótico de Ogden y Richards al ámbito de las expresiones lingüísticas ${ }^{10}$ :

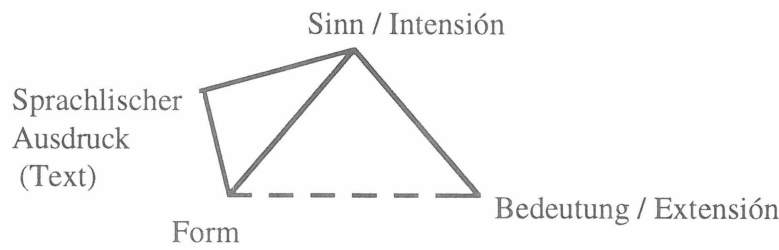

Figura 1

Según este esquema, toda expresión lingüística, p. ej. un texto de lengua natural, es resultado de la combinación de un sentido ('Sinn') o de una intensión (en el caso del texto de un macrosignificado) y de una forma (macrosignificante), entre los que se da una relación semántico-intensional. Con su extensión o 'Bedeutung' la expresión lingüística mantiene una relación semántico-extensional. En consecuencia, en opinión de Petöfi el texto se configura en torno a dos ámbitos: el de la intensión y el de la extensión. El primero de ellos es de naturaleza cotextual, interno al texto; el segundo es contextual, externo al texto, y presenta, además de la dimensión contextual-extensional, una dimensión contextualpragmática. Petöfi llama al primer ámbito 'Textstruktur' y al segundo 'Weltstruktur', y los dos forman el núcleo de su modelo teórico textual que él denomina TeSWeST, acrónimo de 'Textstruktur-Weltstruktur-Theorie'. La TeSWeST, en cuanto modelo semiótico, abarca, de este modo, tanto la forma como el sentido textual (la intensión del texto), pero también el

\footnotetext{
9 'Bedeutung' para Frege indica la relación de una expresión con una dimensión extralingüística; es lo que Lyons denomina 'reference'. 'Sinn', en cambio, tal como también precisa Lyons, alude a una relación intralingüística; concretamente es el significado en la acepción saussureana. Por su parte, Carnap entiende por 'Intension' las condiciones generales que debe reunir un denotatum para que pueda ser expresado por un término lingüístico es el significado de una expresión. La 'Extension' es la clase de los denotata designados o significados por el signo lingüístico. Vid. G. Frege, «Über Sinn und Bedeutung», en G. Frege, Funktion, Begriff, Bedeutung. Fünf logische Studien, ed. de G. Patzig (Göttingen: Vandenhoeck \& Ruprecht, 1962), pp. 40-65. G. Frege, «Über Begriff und Gegenstand», en G. Frege, Funktion, Begriff, Bedeutung, op. cit., pp. 66-80. R. Carnap, Meaning and Necessity (Chicago-London: University of Chicago Press, $2^{\mathrm{a}}$ ed., 1956). R. Carnap, «Significación y sinonimia en las lenguas naturales», en E. Coumet/ D. Ducrot/ J. Gattegno (eds.), Lógica y lingüística (Buenos Aires: Nueva Visión, 1978), pp. 111-125. Vid. también H. Kubczak, Das Verhältnis von Intension und Extension als sprachwissenschaftliches Problem (Tübingen: Narr, 1975).

10 Vid. J. S. Petöfi, «Sémantique, pragmatique, théorie du texte», en J. S. Petöfi, Vers une théorie partielle du texte, Papiere zur Textlinguistik, 9, (Hamburg: Buske, 1975), pp. 81-111, aquí pp. 86 y ss. J. S. Petöfi, «Meaning, Text Interpretation, Pragmatic-semantic Text Classes», Poetics 11 (1982), pp. 453-491.
} 
correlato extensional o denotatum del texto (su 'mundo posible'), por lo que se configura en torno a la tríada formada por 'Text-Intension-Extension'11.

Por su parte, T. Albaladejo Mayordomo, precisando la TeSWeST de Petöfi, distingue en el proceso comunicativo-textual dos elementos centrales: el texto de lengua natural y la estructura de conjunto referencial ${ }^{12}$. El texto de lengua natural está formado por la manifestación textual lineal y por la base textual. La primera, que forma el significante textual, está constituida por el conjunto de las estructuras superficiales de los enunciados que componen el texto; y la segunda, que pertenece al ámbito intensional del texto, corresponde al conjunto de la organización textual subyacente que es evidenciada por la manifestación textual lineal. En la base textual se encuentra la estructura de sentido, compuesta por las relaciones sintácticas y semántico-intensionales de la macroestructura o estructura profunda textual global, y por el mecanismo transformativo-ordenador, un bloque de informaciones de ordenación, encargado de enlazar la estructura de sentido con la manifestación textual lineal. Además, el texto de lengua natural expresa un referente constituido como extensión: la estructura de conjunto referencial. Esta estructura constituye la organización semánticoextensional del conjunto de objetos, hechos o situaciones expresados por el texto de lengua natural. En consecuencia, es objeto de la semántica extensional el "estudio del referente y de la representación textual de éste, así como de la relación entre texto y referente"13. Con el siguiente triángulo, que se orienta en el de Petöfi (Figura 1), Albaladejo visualiza sus consideraciones lingüístico-textuales ${ }^{14}$ :

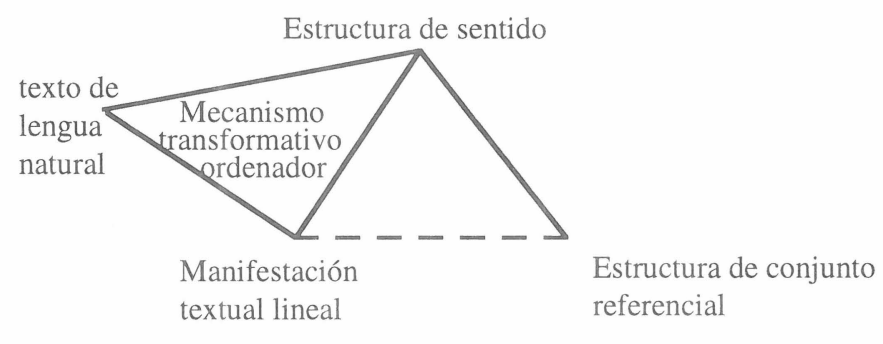

Figura 2

En este modelo el componente semántico-extensional, que alude a la asignación de un denotatum al texto, y por ello atañe también a la recepción textual, es un elemento esencial.

\footnotetext{
11 Vid. J. S. Petöfi, Transformationsgrammatiken und eine ko-textuelle Texttheorie. Grundfragen und Konzeptionen (Frankfurt am Main: Athenäum, 1971). J. S. Petöfi, «Towards an Empirically Motivated Grammatical Theory of Verbal Texts», en J. S. Petöfi/ H. Rieser (eds.), Studies in Text Grammar (Dordrecht: Reidel, 1973), pp. 205-275. J. S. Petöfi, Vers une théorie partielle du texte, op. cit.

12 Vid. T. Albaladejo Mayordomo, Teoría de los mundos posibles y macroestructura narrativa. Análisis de las novelas cortas de Clarín (Alicante: Universidad de Alicante, 1986), pp. 42 y ss. T. Albaladejo, Semántica de la narración: la ficción realista (Madrid: Taurus, 1992), pp. 24 y ss.

13 T. Albaladejo Mayordomo, «La semántica extensional en el análisis del texto narrativo», en G. Reyes (ed.), Teorías literarias en la actualidad (Madrid: El Arquero, 1989), pp. 185-201, aquí p. 188.

14 Vid. T. Albaladejo Mayordomo, Teoría de los mundos posibles y macroestructura narrativa, op. cit., p. 44.
} 
Concretamente se considera que el denotatum o correlato extensional de un texto es un 'mundo'. Entre los mundos posibles se incluye no sólo el mundo ficcional, verosímil o no, sino también el mundo objetivo y real, el mundo de lo 'verdadero'. Se entiende que ese mundo real, al configurarse lingüísticamente, se incorpora al texto en forma de intensión, y que por medio de la dimensión intensional del texto se expresa y se comunica lingüísticamente esa realidad. En ese caso, el autor de un texto transmite al receptor unas informaciones que son resultado de la representación semántica del mundo objetivo ${ }^{15}$. De este modo, dado que el autor de un texto puede elaborar "estructuras del conjunto referencial que son parte del mundo real objetivo"16, y que el texto es un signo que transmite esa información elaborada por su autor, la recepción adecuada será aquélla que logre establecer en el ámbito extensional "un modelo de mundo coincidente con el establecido por el productor en su proceso de elaboración textual"17, y obtenga, además, en el ámbito intensional, "la estructura de sentido, o conjunto de informaciones intensionales del texto, a partir de la superficie o manifestación textual que se le presenta"18. Por consiguiente, expresado de manera abreviada, la comunicación lingüística que se realice por medio de un texto quedará reducida a una actividad de codificación y descodificación de información.

La comunicación lingüística de los contenidos se produce porque éstos, que poseen una organización en lo que respecta a su situación en la extensión, son textualizados, son incorporados por los productores a sus textos, a partir de los cuales los receptores, por su parte, los obtienen en sus análisis, en sus actos de recepción ${ }^{19}$.

Es decir, la recepción del texto será un proceso inverso y simétrico al de su producción:

La recepción del texto de lengua natural es un proceso complejo en el que el receptor recorre, en sentido inverso, el camino comunicativo seguido por el productor en su proceso de producción; por ello el proceso de recepción finaliza con el establecimiento del modelo del mundo y la obtención de la estructura de conjunto referencial, actividades comunicativas con las que se había iniciado el proceso de producción textual ${ }^{20}$.

O bien, en palabras de H. F. Plett, quien también es explícito al respecto:

Sender ist der Textverfasser; seine Aufgabe ist die Enkodierung (Vertextung) einer Information in Sprachzeichen. Textempfänger ist der Hörer/Leser, der die gesendete Nachricht dekodiert (enttextet) ${ }^{21}$.

El fenómeno de la comunicación lingüístico-textual se entiende así, desde esta perspectiva, como un proceso mediante el cual un emisor, sea éste simple o múltiple,

15 Vid. ibid., pp. 52, 58, 69, 79 y 85-87.

${ }^{16}$ Ibid., p. 58.

17 Ibid., p. 63.

18 Ibid., p. 68

19 Ibíd., p. 85

20 T. Albaladejo, Semántica de la narración, op. cit., p. 29.

${ }^{21}$ H. F. Plett, Textwissenschaft und Textanalyse. Semiotik, Linguistik, Rhetorik (Heidelberg: Quelle \& Meyer, $2^{\mathrm{a}}$ ed., 1979), p. 44. 
transmite a un receptor (simple o múltiple), a través de una dimensión textual que actúa como canal o soporte físico (el medio), un mensaje compuesto de signos, que ha sido elaborado según un código (una lengua) determinado. El mensaje que comunica el emisor apunta a un objeto (el referente, lo representado), al que también se refiere el destinatario tras descodificar el mensaje, siempre y cuando éste use correctamente el código. Dado que, primariamente, el mensaje se orienta hacia un objeto (real o ficticio), se estima que la función referencial o denotativa es la más importante de todo proceso comunicativo. Se considera que el acto de comunicación resulta 'fallido' cuando el receptor no capta toda la información codificada en el mensaje, que el emisor desea transmitirle, o sea, cuando el destinatario no logra identificar el referente del mensaje.

De este modo, se conceptúa la comunicación lingüístico-textual, en lo esencial, como transmisión de información: en el proceso comunicativo el emisor usará el lenguaje siguiendo determinadas reglas convencionales para la transmisión o intercambio de información o pensamientos. Y el medio utilizado en la comunicación, el texto, es concebido como una entidad que transporta o traslada una información, o sea que encierra un significado. En este sentido, según R. Burkart, "Medien sind daher als Transportmittel zu begreifen: sie transportieren die zu vermittelnden Bedeutungsinhalte in Form von (Ent-) Äußerungen der Lebewesen zwischen diesen hin und her"22.

Por eso mismo los modelos que asumen esta concepción de la comunicación lingüístico-textual constituyen, con frecuencia, la señal utilizada como conducto del mensaje en el auténtico centro de la atención investigadora y sugieren la existencia de una realidad informativa única, estable y autónoma, lo que implica o presupone, necesariamente, una epistemología u ontología realista: la información codificada en el mensaje se refiere a una realidad extralingüística, y los signos utilizados para su transmisión tienen un significado fijo e invariable que reproduce esa realidad, y que el receptor ha de reconocer o descubrir del modo más exacto posible utilizando adecuadamente el código lingüístico.

Esta perspectiva, que hemos convenido en llamar sustancialista por cuanto tiene su fundamento en la supuesta 'sustancia' del signo lingüístico, considera el texto, sea éste literario o no, como "strukturierte, thematisch abgeschlossene Grundeinheit der sprachlichen Kommunikation"23, como una unidad lingüística cerrada, fija e invariable, en la que el lector ha de tratar de reconocer su sentido inmanente. Consiguientemente, se entiende que el texto es un signo lingüístico, o mejor, un macrosigno formado por otros signos lingüísticos integrados en él ${ }^{24}$. Los signos lingüísticos que componen el macrosigno del

${ }^{22}$ R. Burkart, Kommunikationswissenschaft. Grundlagen und Problemfelder. Umrisse einer interdisziplinären Sozialwissenschaft (Wien-Köln: Böhlau, 1983), p. 26.

${ }^{23}$ R. Conrad (ed.), Lexikon sprachwissenschaftlicher Termini (Leipzig: Bibliographisches Institut Leipzig, $2^{\mathrm{a}}$ ed., 1988), p. 246.

24 Vid. a modo de ejemplo J. Mukarovsky, «Die Kunst als semiologisches Faktum», en J. Mukarovsky, Kapitel aus der Ästhetik (Frankfurt am Main: Suhrkamp, 4ª ed., 1982), pp. 138-174, aquí p. 138. P. Hartmann, «Texte als linguistisches Objekt», en W.-D. Stempel (ed.), Beiträge zur Textlinguistik (München: Fink, 1971), pp. 9-29, aquí p. 10. E. Gülich/ W. Raible, Linguistische Textmodelle. Grundlagen und Möglichkeiten (München: Fink, 1977), p. 25. H. F. Plett, op. cit., pp. 39 y 42-43. C. Segre, «A modo de conclusión: hacia una semiótica integradora», en 
texto no sólo mantienen relaciones sintácticas (la relación signo-signo) y semánticas (la relación signo-objeto), sino también relaciones pragmáticas (la relación del signo con el usuario y el contexto de comunicación $)^{25}$. Pero se estima que estos tres niveles de relaciones son niveles del propio signo; que el texto, en cuanto signo lingüístico, participa en esas relaciones como una dimensión autónoma que es determinante en el proceso de recepción; y que es función del receptor, o en su caso del intérprete, explicitar y aclarar la estructura significativa y referencial del texto mismo. Así, la dimensión pragmática del texto se valora simplemente como una más, junto a la sintáctica y a la semántica.

Esta concepción sobre el texto y la comunicación lingüístico-textual olvida, sin embargo, "daß Sprechen nicht einfach eine mechanische Abfolge von Zeichenäußerungen ist"26; que las acciones comunicativas no pueden reducirse al establecimiento de una relación diádica entre representaciones fonológicas (significantes) y representaciones semánticas (significados) ${ }^{27}$; que ante todo en el acto de comunicación participan unos sujetos que al poner en relación ambos elementos imprimen su impronta en el mensaje, cargándolo de intencionalidad, y que precisamente por ello se constituyen en el factor fundamental del hecho comunicativo. Los signos lingüísticos son siempre signos para alguien, o sea, para un ser dotado de capacidad cognitiva, creador no neutral de una relación entre entidades antes inconexas (el representante y lo representado), que se modifica al cambiar el sujeto ${ }^{28}$. Emisor y receptor no son simples instancias formales y abstractas: son seres que piensan, sienten y manifiestan diferentes deseos, necesidades o capacidades; son individuos que se comunican entre sí en situaciones muy específicas y desde unas circunstancias sociales, ideológicas o culturales por lo general distintas. Por tal motivo los signos que componen el lenguaje natural humano no pueden remitir inequívocamente, por sí mismos, a ideas, objetos o situaciones. El signo no es 'sustancia', su referente no son hechos u objetos independientes de los actores del discurso; sus componentes tampoco son 'formas puras', sino unidades de naturaleza semiótica, relacional y funcional que se articulan gracias a la actividad constructiva del sujeto cognoscente.

En definitiva, entendemos que el hecho comunicativo lingüístico-textual no es un proceso dirigido unidireccionalmente (A envía un mensaje a B), sino que es, ante todo, un proceso transaccional, en cuyo transcurso un autor, en una situación de producción determinada, produce un texto al que unos receptores, en una situación de recepción concreta, asignan un sentido específico ${ }^{29}$. La recepción efectuada integra, además de los datos

J. M. Díez Borque (ed.), Métodos de estudio de la obra literaria (Madrid: Taurus, 1985), pp. 655-681, aquí p. 659. T. Albaladejo Mayordomo, Teoría de los mundos posibles y macroestructura narrativa, op. cit., p. 39. J. Schulte-Sasse/ R. Werner, Einfïhrung in die Literaturwissenschaft (München: Fink, 6a ed., 1990), p. 99.

25 Vid. H. F. Plett, op. cit., p. 52.

26 B. Imhasly/ B. Marfurt/ P. Portmann, Konzepte der Linguistik. Eine Einführung (Wiesbaden: Aula, $3^{\mathrm{a}}$ ed., 1986), p. 73.

27 Vid. M. V. Escandell Vidal, Introducción a la pragmática (Barcelona: Anthropos, 1993), p. 17.

28 Vid. S. Gutiérrez Ordóñez, Introducción a la semántica funcional (Madrid: Síntesis, 1989), p. 16.

29 "A reading event is a transaction among reader and text, where the nature of that transaction is shaped by the situation in which the reading takes place" [D. Vipond/ R. A. Hunt, «Literary Processing and Response as 
textuales, un amplio sistema de presuposiciones del receptor, compuesto por su saber, intenciones, deseos e intereses, así como por las características de la situación de recepción.

En ese proceso receptivo el único contacto posible es el que se establece entre el objeto material textual y el sujeto lector, quien es a su vez productor de sentido. Pues, dado que la comunicación textual es una comunicación no reversible y a distancia, en la que autor y lector no están simultáneamente presentes, e incluso pueden pertenecer a épocas distintas, esa comunicación no podrá efectuarse entre autor y lector reales. Tampoco entre autores y lectores imaginarios, precisamente por el carácter ficticio que éstos poseen. La comunicación lingüístico-textual "es cruzada: va del autor real al lector imaginario, y del lector real al autor imaginario"30. Por eso se puede decir que en este tipo de comunicación la tríada autor-texto-receptor se divide en dos díadas: autor-texto y texto-receptor ${ }^{31}$. Y será sólo de la segunda díada de donde surja efectivamente la comunicación, configurándose ésta como un modo de comunicación unilateral.

Así y todo, el autor desempeña una función ciertamente imprescindible, al ser el garante de que una dimensión física pueda ser reconocida como texto, o sea, al ser el productor de unos estímulos verbales que posibilitan la acción comunicativa. Pero para ese autor el receptor suele ser desconocido, mientras que al lector le es imposible apelar al autor, entre otras razones, "porque el emisor, una vez acabado el mensaje, queda frente a éste en la misma situación que cualquier destinatario"32. Por consiguiente, hasta se puede afirmar que la comunicación que establece el texto

no requiere el contacto, ni siquiera indirecto, entre emisor y destinatario: tan es así que $<$ el texto $>$ mantiene su eficacia a través del tiempo sobre un conjunto de lectores que el emisor no puede prever y menos aún individuar, y aun cuando el emisor haya sido eliminado no sólo como persona física, sino hasta como nombre ${ }^{33}$.

En conclusión, la comunicación lingüístico-textual se realiza exclusivamente entre la materialidad textual, construida por el autor real, y el lector concreto. Y de este encuentro resultará el sentido específico que ese lector otorgue al texto, del cual él es el único responsable. Esa actividad comunicativa se evidencia así, ante todo, como un proceso dinámico de construcción significativa, como un proceso creativo en el que los lectores perciben una materialidad determinada como texto y le asignan sentidos. De este modo,

Textverstehen <wird> als eine konstruktive, kontinuierliche Tätigkeit augefaßt $<\ldots>$ und nicht als eine bloße Dekodierung des Gesagten bzw. als eine Rekonstruktion

Transaction: Evidence for the Contribution of Readers, Texts and Situations», en D. Meutsch/ R. Viehoff (eds.), Comprehension of Literary Discourse. Results and Problems of Interdisciplinary Approaches (Berlin-New York: de Gruyter, 1989), pp. 155-174, aquí p. 158].

30 M. Cáceres Sánchez, Lenguaje, texto, comunicación. De la lingüística a la semiótica literaria (Granada: Universidad de Granada, 1991), p. 48. Vid. también R. Núñez Ramos, «La literatura, comunicación a distancia», Noésis 3 (1986).

${ }^{31}$ Vid. C. Segre, «A modo de conclusión: hacia una semiótica integradora», op. cit., p. 666.

32 C. Segre, Principios de análisis del texto literario (Barcelona: Crítica, 1985), p. 18.

33 C. Segre, «A modo de conclusión: hacia una semiótica integradora», op. cit., pp. 665-666. 
des Gemeinten, als eine einfache Übertragung der Textinformationen in eine mentale Repräsentation ${ }^{34}$.

Precisamente por esa razón entendemos que el texto siempre es un medio utilizado por los comunicantes para la comunicación; que antes de ser un signo de algo, el texto es un signo para alguien, por lo que los signos que se le atribuyen no se relacionan por sí mismos entre sí, sino que, por el contrario, son puestos en relación por esos mismos comunicantes; y que, en definitiva, el texto tampoco apunta por sí mismo a un referente, sino sólo cuando le es asignado en el proceso de comunicación. En rigor, también los aspectos sintácticos y semánticos del texto, es decir, todo el texto, únicamente pueden existir en un nivel de relaciones pragmáticas. O sea, el texto no es una unidad ya realizada que se inserte en unas relaciones pragmáticas, sino que esas mismas relaciones son parte constitutiva del propio texto. "Es gibt also keinen Text 'an sich', sondern nur den kommunikativ aktualisierten Text"35. O lo que es lo mismo, "man kann 'Zeichen' nicht von seiner Verwendung trennen" 36 .

De acuerdo con estas consideraciones estimamos conveniente conceptuar el texto, esencialmente, "nicht als Zeichen, sondern als materielles Substrat der Bedeutungsbildung, d. h. als Zeichenträger"37. Desde esta perspectiva el texto se configura como una dimensión física que se constituye en signo solamente en el marco de una acción comunicativa y en función de unos individuos comunicantes. En consecuencia, la recepción ya no sería un acto externo al texto, sino ante todo un proceso constitutivo del propio texto, gracias al cual éste se actualiza comunicativamente de manera continuada.

A esta consideración del texto y de su recepción subyace la idea de que la particularidad esencial del fenómeno comunicativo lingüístico-textual no es la transmisión mediante un texto de la información elaborada por un autor, sino la generación de información o sentido que el receptor realiza en su propio ámbito cognitivo a raíz de las acciones comunicativas del sujeto emisor. Pues, en lo fundamental,

die reale Welt, die wir mittels sensorischer Rezeptoren so unmittelbar als real und objektiv erleben, ist ein Konstrukt unseres Gehirns, das die Reize der Umgebung, in der der menschliche Organismus lebt, auf eine artspezifische Weise verarbeitet und zu einem globalen Weltkonzept zusammensetzt ${ }^{38}$.

\footnotetext{
34 W. Heinemann/ D. Viehweger, Textlinguistik. Eine Einführung (Tübingen: Niemeyer, 1991), p. 116.

35 K. Kasics, Literatur und Fiktion. Zur Theorie und Geschichte der literarischen Kommunikation (Heidelberg: Winter, 1990), p. 22.

${ }^{36}$ H. Hörmann, Einführung in die Psycholinguistik (Darmstadt: Wissenschaftliche Buchgesellschaft, $3^{\text {a }}$ ed., 1991), p. 27.

37 G. Martens, «Was ist ein Text?. Ansätze zur Bestimmung eines Leitbegriffs der Textphilologie», Poetica 21/1-2 (1989), pp. 1-25, aquí p. 11.

38 M. Schwarz, Kognitive Semantiktheorie und neuropsychologische Realität. Repräsentationale und prozedurale Aspekte der semantischen Kompetenz (Tübingen: Niemeyer, 1992), p. 40.
} 
En rigor, "el fenómeno de comunicación no depende de lo que se entrega, sino de lo que pasa con el que recibe" 39 , de cómo el destinatario describa e interprete los estímulos que recibe y qué consecuencias tenga este hecho en su conducta. En este sentido, la comunicación no se configura como un intercambio de información, sino como construcción paralela de información en el ámbito cognitivo de los individuos que se comunican.

Information ist etwas, das wir aktiv schaffen, wo immer es die Umstände 'erlauben' und wo immer wir sie zwischen die Fakten der Welt hineinprojizieren können - letzten Endes sind wir es, die die Welt sinnvoll und informationshaltig machen ${ }^{40}$.

Consiguientemente, por información se debe entender el efecto que una señal ejerce sobre la estructura y función de un sistema cognitivo, sobre su conducta y sus estados de percepción y conciencia, en el sentido que ese efecto no es producto de una información transmitida y recibida, sino, en cualquier caso, construida o generada. Así, la información, concebida como 'sentido para alguien', es una dimensión dependiente del sujeto -lo que no quiere decir que sea necesariamente 'subjetiva' ya que el sujeto es un individuo socializado-, que el organismo en cuestión construye en su propio ámbito cognitivo a raíz de una acción comunicativa ${ }^{41}$. De aquí se desprende que no puede haber una interacción comunicativa directa o inmediata entre los seres humanos. Estos interactúan en el proceso comunicativo según sus respectivas determinaciones estructurales sobre la base de las descripciones y percepciones que cada organismo elabora y sintetiza en su propio ámbito cognitivo y de interacción, lo que configura la manera específica cómo cada individuo comunicante experimenta los acontecimientos externos y a los demás organismos ${ }^{42}$.

El lenguaje se evidencia, desde esta perspectiva, como un sistema de orientación comunicativa; es decir, el comportamiento lingüístico es fundamentalmente un comportamiento de orientación: la conducta lingüística "orientiert den zu Orientierenden innerhalb seines kognitiven Bereiches auf Interaktionen hin, die unabhängig sind von der

${ }^{39}$ H. R. Maturana/ F. J. Varela, El árbol del conocimiento. Las bases biológicas del conocimiento humano (Madrid: Debate, 1990), p. 169.

40 H. Hörmann, Meinen und Verstehen. Grundzüge einer psychologischen Semantik (Frankfurt am Main: Suhrkamp, $3^{\text {a }}$ ed., 1988), p. 470.

41 Vid. S. J. Schmidt, «Texte verstehen - Texte interpretieren», en A. Eschbach (ed.), Perspektiven des Verstehens (Bochum: Brockmeyer, 1986), pp. 75-103, aquí p. 88.

42 A este respecto estimamos con J. Vázquez que en la experiencia perceptiva interpretación y percepción forman parte de un mismo acto cognitivo, único e indivisible, en el que no son disociables. Ello explica que dos sujetos puedan realizar diferentes percepciones a partir de un mismo objeto empírico; en ese caso, la diferencia en la modalidad perceptiva, el sentido de lo percibido, no radica en las impresiones sensoriales recibidas, sino en la organización que de esas impresiones realiza el sujeto en el transcurso de la experiencia perceptiva. Así, "si un niño sale al jardín después de haber asistido a una clase de botánica verá pétalos, estambres y pistilos allî donde antes veía simplemente una flor. Sus imágenes retinianas seguirán siendo las mismas que antes de haber asistido a la clase de botánica, pero la organización de lo sensible, indudablemente, ha variado y, con ella, el sentido de lo percibido" [J. Vázquez, Lenguaje, verdad y mundo. Modelo fenomenológico de análisis semántico (Barcelona: Anthropos, 1986), p. 114]. 
Art der orientierenden Interaktionen selbst"43. O lo que es lo mismo, la conducta lingüística sólo es posible sobre la base de la interacción comunicativa; y la función concreta del lenguaje que la origina consiste en orientar en su propio ámbito cognitivo a los participantes comunicativos al objeto de provocar operaciones consensuadas de naturaleza lingüística, cognitiva, efectiva, etc., y no en remitirlos a entidades autónomas o independientes ${ }^{44}$. En rigor, el lenguaje se manifiesta primariamente, en cuanto producto enteramente social y funcional, como un sistema de conductas y no como un sistema de signos. "Sprechen ist ein intentionales Verhalten $\langle\ldots$. . Es stellt eine Form sozialen Handelns dar <..., eine> besondere Form kommunikativen Handelns" 45 .

De lo expuesto se deduce que el lenguaje sólo puede funcionar para los sujetos que interactúan de manera connotativa y no como un sistema denotativo de símbolos para la transmisión de información. "La denotación, concebida como ley del proceso significativo, no pasa de ser un espejismo, ya que el lenguaje no es tan sólo una entidad semiótica clausa en su propia estructura sino más bien una actividad de los grupos sociales que se desenvuelven en un ambiente determinado"46. En rigor, aunque la orientación producida como resultado del proceso comunicativo sea ciertamente motivada o estimulada por el mensaje del organismo orientador, en su configuración concreta es independiente de lo que ese mensaje representa para el organismo que provoca la orientación. Es decir, el resultado de la interacción comunicativa que se produce en el ámbito cognitivo del organismo orientado no está determinado por el significado que el mensaje tiene en el ámbito cognitivo del orientador, por mucho que ambos ámbitos cognitivos puedan coincidir. El mensaje 'emitido' solamente puede ejercer, de hecho, un efecto connotativo sobre el individuo que es objeto de la orientación.

En sentido estricto no puede haber, por tanto, una transmisión de pensamientos o información entre los interlocutores. Lo que sí se puede intercambiar en el proceso comunicativo lingüístico-textual son medios de comunicación ópticos o acústicos que provocan unos estímulos que son interpretados de forma individual por los receptores. O sea, lo que en realidad se transmite son señales físicas, impulsos eléctricos, y no pensamientos o informaciones. Estos surgen únicamente en el ámbito cognitivo de cada sujeto actante bajo unas condiciones individuales, culturales y sociales muy específicas y particulares. De esta manera, con la ayuda de expresiones lingüísticas y medios de

\footnotetext{
${ }^{43}$ H. R. Maturana, Erkennen: Die Organisation und Verkörperung von Wirklichkeit. Ausgewählte Arbeiten zur biologischen Epistemologie (Braunschweig-Wiesbaden: Vieweg, $2^{\mathrm{a}}$ ed., 1985), p. 55.

44 También S. I. Hayakawa señala que se hace uso del lenguaje a fin de establecer una comunidad entre los interlocutores: "<...> bei der Auswahl des Gesprächsstoffes <ist> ein Grundsatz wirksam. Da der Zweck $\langle\ldots\rangle$ die Herstellung einer Gemeinsamkeit ist, sind wir sorgsam darauf bedacht, Gesprächsstoffe auszuwählen, über die unmittelbar Übereinstimmung möglich ist" [S. I. Hayakawa, Sprache im Denken und Handeln (Darmstadt: Darmstädter Blätter, 1976), p. 103].

45 W. Kallmeyer et al., Lektürekolleg zur Textlinguistik, vol. I: Einführung (Königstein/Ts.: Athenäum, $4^{\mathrm{a}}$ ed., 1986), p. 15. Vid. también F. Meix Izquierdo, La dialéctica del significado lingüístico (Salamanca: Universidad de Salamanca, $2^{a}$ ed., 1994), p. 166.

${ }^{46}$ F. Meix Izquierdo, op. cit., p. 153. Vid. también pp. 154, 156 y 194 y ss.
} 
comunicación no hay instrucción o determinación, sino a lo sumo una activación u orientación en el ámbito de la interacción, que puede adoptar modalidades muy diversas ${ }^{47}$.

Como consecuencia de lo expuesto, se puede afirmar que en la interacción lingüística siempre permanecemos en un ámbito de descripciones, aun cuando pretendamos hablar de la realidad ontológica: todo lo que decimos se reduce a una descripción ${ }^{48}$. Así, no se puede atribuir significado a las unidades y expresiones lingüísticas como una propiedad que éstas poseen de modo autónomo. "El significado lingüístico se construye socialmente, no pertenece a las palabras como algo inherente a ellas"49. O sea, el significado no es una dimensión que es portada por un significante. En sí y por sí misma la expresión oral de un enunciado no es más que la emisión de unos sonidos; y su expresión escrita es tan sólo la exposición de unos trazos de color negro sobre un fondo blanco. Pues son únicamente los propios interlocutores en circunstancias socio-culturales concretas los que transforman esos fenómenos acústicos y objetos visuales en fonemas y grafemas con significado. Y sobre la base de esas descripciones, que ellos mismos realizan, se orientan en el proceso comunicativo $^{50}$. Es decir, "en el lenguaje toda estructura se explica por su rendimiento funcional, por su inserción en la vida social y en la práctica comunicativa de la colectividad" 51 .

En ese proceso comunicativo la atribución de significado se efectúa en dependencia del valor orientativo que se le otorga al fenómeno acústico o gráfico, y de acuerdo con la función operativa que desempeña su descripción en el ámbito cognitivo del individuo en cuestión. En ese caso, los diferentes significados que se asignen a las expresiones lingüísticas serán diferencias en la modalidad que la orientación comunicativa adquiere, o sea, en lo concerniente a su relevancia operativa para el sistema cognitivo.

En tanto es de la función operativa de donde depende su significado, y no de su supuesta 'sustancia', las expresiones lingüísticas no pueden ser consideradas como si representaran o correspondieran con hechos u objetos (reales o ficticios) existentes independientemente en la realidad, como así lo estiman las concepciones semánticas realistas. La relación que se establece entre expresión lingüística y 'realidad' existe únicamente en el ámbito cognitivo de cada organismo, pues fuera de ese ámbito las unidades léxicas, frases o enunciados no significan nada.

\footnotetext{
47 "Daher <müssen> kommunikative Äußerungen eher als Stimuli (oder 'Turbulenzen') im Interaktionsbereich des Adressaten angesehen werden $\langle\ldots\rangle$, die entsprechend dem gegebenen Zustand desselben zu bestimmten individuendeterminierten Transformationen führen, die nur wenig oder gar nichts mit der originalen 'Botschaft' bzw. dem 'Intendierten' seitens des 'Senders' oder Beobachters gemeinsam haben!" [W. K. Köck, «Kognition Semantik - Kommunikation», en S. J. Schmidt (ed.), Der Diskurs des Radikalen Konstruktivismus (Frankfurt am Main: Suhrkamp, 1987), pp. 340-373, aquí p. 370]

48 Vid. H. R. Maturana, op. cit., p. 73.

${ }^{49}$ F. Meix Izquierdo, op. cit., p. 201.

${ }^{50}$ Ello explica que el significado lingüístico sea esencialmente connotativo, esto es, "intersubjetivo, pragmático y adaptado a la situación" (vid. ibíd., pp. 195-196).

51 Ibid., p. 173.
} 
La referencia se ha de conceptuar, por esa razón, como una operación que se realiza íntegramente en nuestra conciencia, y no como una operación de comparación de las expresiones lingüísticas con el mundo extralingüístico objetivo y real. Conceptos como los de referencia o denotación solamente pueden designar las relaciones existentes entre las diversas descripciones que un organismo genera en su propio ámbito cognitivo, y no fenómenos, entidades o sucesos independientes de ese mismo ámbito en cuanto 'cosas en sí'. O sea, la referencia expresa el carácter operativo o funcional de ciertas descripciones con relación a otras descripciones que de alguna manera están vinculadas a ellas. De esta manera se puede decir que la descripción X designa, se refiere o significa la descripción Y; y esa relación únicamente existe en el ámbito cognitivo del sujeto que la ha realizado. En definitiva, el referente de las expresiones lingüísticas está compuesto exclusivamente por estructuras cognitivas pertenecientes al mundo conceptual de nuestra conciencia, por objetos, lugares, seres, acontecimientos, estados o ideas propios de un mundo 'proyectado' por el sujeto de la cognición ${ }^{52}$

Por poner un ejemplo que ilustre esta concepción de la referencia, en la expresión "Heinrich Böll vivió gran parte de su vida en Colonia", el nombre de Heinrich Böll no se refiere, designa o significa primariamente un ser concreto que existió en cuanto entidad objetiva en sí misma; más bien los interlocutores, al emitir o recibir esa expresión, relacionan el nombre de Heinrich Böll con un modelo cognitivo específico y particular que ellos disponen de esa persona, o sea, con una descripción previamente existente a la emisión o recepción de la expresión, o conformada durante el proceso comunicativo. Así, para unos Heinrich Böll será un Premio Nobel de literatura, o bien, un escritor representativo de la literatura alemana de posguerra; para otros, en cambio, será la 'conciencia crítica' de la Républica Federal Alemana, o incluso 'un comunista católico' como alguna vez se dijo. El referente de 'Heinrich Böll' lo constituirán, en todo caso, secciones de diferentes modelos de realidad con las que los interlocutores relacionan la expresión, y no un determinado ser o elemento de la realidad misma objetivamente reconocible, portador de un único sentido. Algo semejante ocurre con cualquier otro ser, estado, proceso, acción o idea expresado lingüísticamente.

En suma, el referente de las expresiones lingüísticas se evidencia como un constructo dependiente estrictamente del sujeto, de su modelo de realidad, capacidades, intenciones o presuposiciones. En rigor, sólo con el sujeto, es decir, con un sistema cognitivo, se puede relacionar y explicar el problema de la referencia, así como también dilucidar la condición de

\footnotetext{
52 Vid. R. Jackendoff, Semantics and Cognition (Cambridge/Mass.: The MIT Press, 1983), p. 36. J. Vázquez lo explica de la siguiente manera: "En la medida que el referente de los términos categoremáticos no lo constituyen las impresiones sensibles, sino el sentido que resulta de su organización en los actos perceptivos, este referente ya no es algo material ajeno al propio sujeto perceptor, sino una unidad cultural que $<\ldots>$ no existe fuera del mundo y de los vocablos, pero que tampoco puede ser identificada con unos supuestos datos sensibles $\langle\ldots\rangle$. El referente de una descripción definida no lo constituyen una vez más los objetos o situaciones en cuanto cosas en sí, sino el sentido perceptivo bajo el que dichos objetos o situaciones se nos han hecho presentes o pueden llegar a hacérsenos en las experiencias empíricas correspondientes" [J. Vázquez, op. cit., pp. 115 y 145].
} 
cualquier conjunto referencial, el cual únicamente funciona y existe en ese mismo sistema cognitivo. Es por esa razón que no se puede tener un acceso directo al referente indicado por los signos. El referente de las expresiones lingüísticas es una realidad secundaria y mediata, no primaria o inmediata: los signos y sus relaciones referenciales presuponen un sistema cognitivo y una realidad cognitiva específica que ese sistema configura. Y el signo no reproduce esa realidad ni tampoco indica por sí mismo el grado de complejidad de lo 'opinado'. O lo que es lo mismo, la comunicación lingüístico-textual no es un fenómeno que radique esencialmente en el texto, sino ante todo en los seres humanos que pretenden esa comunicación. Son éstos quienes, en definitiva, a fin de otorgarle un sentido coherente a la materialidad textual, construyen relaciones de referencia infiriendo vínculos temáticosemánticos entre las unidades lingüísticas presentes en la superficie textual, su conocimiento del mundo y la situación comunicativa. 


\section{BIBLIOGRAFÍA}

Acosta, L. A., Cuestiones de lingüística textual. Con una selección bibliográfica (Salamanca: Universidad de Salamanca, 1982).

--, «Fundamentos lingüístico-comunicativos del texto literario I», Revista de Filología Alemana 2 (1994), pp. 13-41.

Albaladejo Mayordomo, T., Teoría de los mundos posibles y macroestructura narrativa. Análisis de las novelas cortas de Clarín (Alicante: Universidad de Alicante, 1986).

--, «La semántica extensional en el análisis del texto narrativo», en G. Reyes (ed.), Teorías literarias en la actualidad (Madrid: El Arquero, 1989), pp. 185-201.

--, $\quad$ Semántica de la narración: la ficción realista (Madrid: Taurus, 1992).

--/ F. Chico Rico, «La Teoría de la Crítica lingüística y formal», en P. Aullón de Haro (ed.), Teoría de la Crítica literaria (Madrid: Trotta, 1994), pp. 175-293.

Bernárdez, E., Teoría y epistemología del texto (Madrid: Cátedra, 1995).

Bühler, K., Sprachtheorie. Die Darstellungsfunktion der Sprache (Stuttgart: Fischer, $2^{\mathrm{a}}$ ed., 1965).

Cáceres Sánchez, M., Lenguaje, texto, comunicación. De la lingüística a la semiótica literaria (Granada: Universidad de Granada, 1991).

Frege, G., «Über Sinn und Bedeutung», en G. Frege, Funktion, Begriff, Bedeutung. Fünf logische Studien, ed. de G. Patzig (Göttingen: Vandenhoeck \& Ruprecht, 1962), pp. 40-65.

--, «Über Begriff und Gegenstand», en G. Frege, Funktion, Begriff, Bedeutung, op. cit., pp. 66-80.

Gutiérrez Ordóñez, Introducción a la semántica funcional (Madrid: Síntesis, 1989).

Hörmann, H., Meinen und Verstehen. Grundzïge einer psychologischen Semantik (Frankfurt am Main: Suhrkamp, $3^{a}$ ed., 1988).

--, Einführung in die Psycholinguistik (Darmstadt: Wissenschaftliche Buchgesellschaft, $3^{\mathrm{a}}$ ed., 1991).

Jackendoff, R., Semantics and Cognition (Cambridge/Mass.: The MIT Press, 1983).

Kallmeyer, W. et al., Lektürekolleg zur Textlinguistik, vol. I: Einführung (Königstein/Ts.: Athenäum, $4^{\text {a }}$ ed., 1986).

Köck, W. K., «Kognition - Semantik - Kommunikation», en S. J. Schmidt (ed.), Der Diskurs des Radikalen Konstruktivismus (Frankfurt am Main: Suhrkamp, 1987), pp. 340-373.

Lyons, J. Introduction to Theoretical Linguistics (Cambridge: University Press, 1968).

--, Semantics (Cambridge: Cambridge University Press, 1977).

Maldonado Alemán, M., «Coherencia y textualidad», Revista de Filología Alemana 3 (1995), pp. 163-186.

--, «Niveles procesuales en la comprensión textual», en Aspectos de didáctica de la lengua y la literatura, Actas del III Congreso Internacional de la Sociedad Española de Didáctica de la Lengua y la Literatura, ed. de P. Guerrero Ruiz y A. López Valero, 2 vols. (Murcia: Universidad de Murcia, 1995), vol. 1, pp. 267-271. 
Maturana, H. R., Erkennen: Die Organisation und Verkörperung von Wirklichkeit. Ausgewählte Arbeiten zur biologischen Epistemologie (Braunschweig-Wiesbaden: Vieweg, 2a ed., 1985).

--l F. J. Varela, El árbol del conocimiento. Las bases biológicas del conocimiento humano (Madrid: Debate, 1990).

Meix Izquierdo, F., La dialéctica del significado lingüístico (Salamanca: Universidad de Salamanca, $2^{a}$ ed., 1994).

Ogden, C. K./ I. A. Richards, The Meaning of Meaning (London: Routledge and Kegan Paul, 10 ed., 1966).

Petöfi, J. S., Transformationsgrammatiken und eine ko-textuelle Texttheorie. Grundfragen und Konzeptionen (Frankfurt am Main: Athenäum, 1971).

--, «Towards an Empirically Motivated Grammatical Theory of Verbal Texts», en J. S. Petöfi/ H. Rieser (eds.), Studies in Text Grammar (Dordrecht: Reidel, 1973), pp. 205275 .

--, «Sémantique, pragmatique, théorie du texte», en J. S. Petöfi, Vers une théorie partielle du texte, Papiere zur Textlinguistik, 9 (Hamburg: Buske, 1975), pp. 81-111.

--, «Meaning, Text Interpretation, Pragmatic-semantic Text Classes», Poetics 11 (1982), pp. 453-491.

Rusch, G., Erkenntnis, Wissenschaft, Geschichte. Von einem konstruktivistischen Standpunkt (Frankfurt am Main: Suhrkamp, 1987).

Schmidt, S. J., «Texte verstehen - Texte interpretieren», en A. Eschbach (ed.), Perspektiven des Verstehens (Bochum: Brockmeyer, 1986), pp. 75-103.

Schwarz, M., Kognitive Semantiktheorie und neuropsychologische Realität. Repräsentationale und prozedurale Aspekte der semantischen Kompetenz (Tübingen: Niemeyer, 1992).

Segre, C., Principios de análisis del texto literario (Barcelona: Crítica, 1985).

--, «A modo de conclusión: hacia una semiótica integradora», en J. M. Díez Borque (ed.), Métodos de estudio de la obra literaria (Madrid: Taurus, 1985), pp. 655-681.

Strohner, H./ G. Rickheit, «Kognitive, kommunikative und sprachliche Zusammenhänge: Eine systemtheoretische Konzeption linguistischer Kohärenz», Linguistische Berichte 125 (1990), pp. 3-23.

Thrane, T., Referential-Semantic Analysis. Aspects of a Theory of Linguistic Reference (Cambridge: Cambridge University Press, 1980).

Vater, H., Einführung in die Referenzsemantik (Köln: Universität Köln, 1986).

--, «Referenzrelationen in Texten», en K. Brinker (ed.), Aspekte der Textlinguistik (Hildesheim-Zürich-New York: Olms, 1991).

--, Einführung in die Textlinguistik. Struktur, Thema und Referenz in Texten (München: Fink, 1992).

Vázquez, J., Lenguaje, verdad y mundo. Modelo fenomenológico de análisis semántico (Barcelona: Anthropos, 1986). 